\title{
The Wyoming Summer Institute for the Study of Conflict Theory and International Security
}

\author{
RAYMOND DACEY \\ College of Business Administration \\ University of Oklahoma
}

The Summer Institute for the Study of Conflict Theory and International Security ${ }^{\prime}$ conducts an annual symposium for the acquisition and dissemination of knowledge of both scientific and practical import in the areas of conflict theory and international security. The principal focus of the Institute is formal, analytic interdisciplinary research in the areas of conflict theory, especially conflict between nations, and international security.

The Institute met July 8-10, 1981, at and under the sponsorship of the University of Wyoming in Laramie. The support of the University of Wyoming, financial and otherwise, is gratefully acknowledged. Particular thanks are due to Dr. Edward H. Jennings, then-President of the University of Wyoming and now President of Ohio State University, and to Todd Sandler, Department of Economics at the University of Wyoming.

The following articles derive from presentations made at the 1981 Laramie meeting of the Institute. The articles by Bueno de Mesquita and Riker, Murdoch and Sandler, McGuire, and Richelson are based

1. The Institute is guided by a steering committee, consisting of Steven Brams (NYU), Michael Intriligator (UCLA), Martin McGuire (Maryland), and Todd Sandler (Wyoming) and is directed by myself. 1 wish to thank these individuals for their extensive contributions.

EDITOR'S NOTE: The first and larger portion of this number of the Journal is a Special Issue on Conflict and International Security, edited by Raymond Dacey and Todd Sandler. The articles by Wagner and Sampson are included as appropriate to the general theme of the issue, but came to the Journal through the normal editorial process and are not the responsibility of the Special Issue editors.

-Bruce Russett

JOURNAL OF CONFLICT RESOLUTION. Vol. 26 No. 2, June 1982 195-198

(C) 1982 Sage Publications, Inc. 
upon formal presentations they made at the meeting. The article by Intriligator is based upon informal presentations he made at both the 1980 and 1981 Laramie meetings.

McGuire presents an economic analysis of the interactive effects of U.S. foreign assistance to Israel upon Israeli allocation of resources and the Middle East arms race. The analysis employs standard economic theory and an extensive data base to arrive at explanations of Israeli economic behavior and the arms acquisition processes followed by various Middle Eastern nations.

Murdoch and Sandler present an analysis of economic influences of member nations upon the stability of an alliance. More specifically, they present a refinement of the joint-product model and thereby formulate an improved account of the effects of jointly produced military goods upon the behavior of member nations. Murdoch and Sandler conclude their article by testing the refined model via an empirical analysis of the economic behavior of NATO nations.

Richelson offers a critical review of the standard indicators of strategic balance and shows that, by the careful selection of an indicator, one can arrive at almost any desired ranking. In particular, Richelson considers those cases wherein alternate indicators provide reversed rankings of strategic forces.

Bueno de Mesquita and Riker present an argument, couched in the language of decision theory, for the merits of nuclear proliferation. Specifically, they address the role of proliferation in the decisionmaking behavior of a nation considering the initiation of a nuclear war. They conclude that the selective proliferation of nuclear armaments can reduce the chance of nuclear war and thus may be conducive to world peace.

Intriligator reviews the major research issues in conflict theory and international security and the application of various analytical tools to those areas. His overview provides an account of the present state of affairs and makes suggestions for further areas of research. There are numerous open issues and many as-yet unknown applications of available tools. The Institute will explore in future meetings the application of these various tools to open issues, and it will pursue the creation of new tools and the study of heretofore untreated problems.

The common ground of the four analytic articles is provided by traditional decision theory. Therein a decision problem is a pair $(\mathrm{S}, \mathrm{A})$ with state-space $S$ and act-space $A$ and a decision maker is a triple ( $f, u$, P) with outcome mapping $f$, utility function $u$, and probability measure 
P. The traditional theory also allows the decision maker to call upon an information system $Y$. The decision maker resolves the initial decision problem by selecting $\mathrm{a}^{*}$ in $\mathrm{A}$ so as to maximize the (unconditional) expected utility $\mathrm{E}[\mathrm{u}(\mathrm{a})]$. Similarly, given an information system $\mathrm{Y}$ and a message $\mathrm{y}$ from that system, the decision maker resolves the revised decision problem by selecting a $\mathrm{y}$ in $\mathrm{A}$ so as to maximize the (conditional) expected utility $\mathrm{E}[\mathrm{u}(\mathrm{a}) \mathrm{y}]$. If we presume that the decision maker knows his or her preferences and beliefs, then the construction of the utility function $u$ and the probability measure $P$ is trivial. In almost all decision problems, the construction of the outcome mapping $f$ and the selection of the optimal information system $\mathrm{Y}^{*}$ are both nontrivial enterprises.

The construction of an outcome mapping for any nontrivial decision problem is itself a difficult decision problem. An outcome mapping is properly a set of triples $(s, a, o)$ such that for each act-state pair $(s, a)$, the decision maker knows that the outcome (or consequence) of performing act $a$ in state $s$ is $o$. The construction of the outcome mapping is thus an epistemic decision problem wherein the decision maker employs theories and models (from physics, economics, and so on) of sufficient epistemic status to predict the outcome of performing each act in each state of nature. The ability of the decision maker to resolve a decision problem rests on the decision maker's ability to construct an outcome mapping for that problem.

The articles by Bueno de Mesquita and Riker, Murdoch and Sandler, and McGuire all present outcome mapping or fragments of outcome mapping for various decision problems. Specifically, the article by Bueno de Mesquita and Riker presents a fragment of the outcome mapping required for the resolution of the decision problem faced by the U.S. government of selecting a policy on nuclear proliferation. The article by Murdoch and Sandler presents an outcome mapping for each member of an alliance required in deciding upon the member nation's contribution to the alliance. The article by McGuire presents the outcome mapping required to resolve the problem faced by the U.S. government of determining the amount and nature of its (foreign) assistance to Israel.

Traditional decision theory, through the economic theory of information, provides an account of the selection of the optimal information system. Included in that account are the costs, both economic and noneconomic, of the system. The article by Richelson presents a critical analysis of various information systems, including the noneconomic 
costs of those systems, each of which is relevant to the problem of deciding on defense expenditures. The present U.S. deliberations on defense expenditures, by which the administration intends to achieve parity with the Soviet Union, constitute an example of just such a decision problem. 